\title{
LA DEFINICIÓN SINONÍMICA \\ EN LA SEXTA EDICIÓN DEL DICCIONARIO DE LA LENGUA \\ CASTELLANA DE LA REAL ACADEMIA ESPAÑOLA*
}

\author{
Natalia Terrón Vinagre y Joan Torruella Casañas (ICREA) \\ Universitat Autònoma de Barcelona
}

\section{RESUMEN}

La sexta edición del Diccionario de la lengua castellana de la Real Academia Española se publicó en 1822, solamente cinco años después de la inmediatamente anterior de 1817 , con la urgencia de resolver la ausencia en el mercado de ejemplares. En su redacción se mantuvieron los mismos criterios acordados para la edición precedente, lo que demuestra la continuidad entre ambas. Sin embargo, en la práctica existen ciertas diferencias que apuntan a una mejora en la precisión de la técnica lexicográfica. Una de estas diferencias destacable es la que afecta a la coherencia entre las definiciones sinonímicas y la remisión. Por ello, el objetivo de este trabajo es el estudio de su relación en el diccionario académico, así como el análisis de las modificaciones que experimentan las definiciones sinonímicas en la edición de 1822. Dicho estudio ha llevado a constatar que, en la sexta edición del diccionario, la Academia estableció una distinción entre las definiciones sinonímicas compuestas por varios equivalentes y las compuestas por un solo equivalente, haciendo uso, en este último caso, del recurso lexicográfico de la remisión para concentrar la definición en una sola entrada (la más «usual»), suprimiendo así definiciones repetidas.

Palabras Clave: definición, sinonimia, remisión, DRAE 1822, lexicografía.

SYNONIMIC DEFINITIONS IN THE SIXTH EDITION OF THE DICCIONARIO

DE LA LENGUA CASTELLANA BY THE REAL ACADEMIA ESPAÑOLA

\section{Abstract}

The sixth edition of the Diccionario de la lengua castellana was urgently published in 1822 by the Real Academia Española, due to the lack of copies of the previous edition that had only been published five years before, in 1817. The same criteria that had been applied in the elaboration of precedent edition were followed, thus demonstrating continuity between both editions. However, in practice there are differences that point at an improvement in the accuracy of the lexicographic technique. One of these differences concerns the coherence between the synonymic definitions and the cross-reference. For this reason, this paper aims to evaluate their relation in the academic dictionary, as well as to analyse the modifications that the synonymic definitions experience in the 1822 edition. This study has led to confirm that in the sixth edition of the dictionary the Academia distinguished between synonymic definitions comprising various equivalents and those that were composed of one equivalent, making use in this case of the cross-reference, a lexicographic resource that concentrated the definition in a single entry (the most common one). By doing so, duplicated definitions were suppressed. KeYwORDs: definition, synonymy, cross-reference, $D R A E$ 1822, lexicography 


\section{INTRODUCCIÓN}

En la tradición lexicográfica académica ha sido recurrente usar la definición sinonímica en la explicación de un lema, se trata de aquellas definiciones en que el definiens está compuesto solamente por una o varias voces semánticamente equivalentes al lema. Este tipo de definición ha sido muy criticada en la lexicografía teórica, ya que plantea sobrados problemas, no solamente por la propia naturaleza de la sinonimia, sino también porque desde el punto de vista de la estructura formal del enunciado definicional su contenido carece de sintaxis y, por lo tanto, no ofrece una explicación de la unidad léxica que se está definiendo, a diferencia de la definición perifrástica, constituida por una perífrasis analítica del lema ( $c f r$. Ahumada Lara 1989: 146). Además, al no ofrecer un análisis semántico de la voz, se apela a la competencia léxica del lector, suponiendo que conoce el significado del vocablo o de los vocablos presentes en el enunciado definicional ( $c f r$. Regueiro Rodríguez 2010: 14). No obstante, desde una perspectiva lexicográfica, este tipo de definición es perfectamente admisible en los casos en que dos unidades léxicas poseen definiciones idénticas, evitando, así, repeticiones de contenido en las entradas (Castillo Peña 1992: 511-512; Trujillo 1994: 76). Las restricciones de uso de los sinónimos a una variedad determinada de la lengua se indican en lexicografía mediante el uso de marcas.

En este sentido, en el diccionario de la Real Academia Española la definición sinonímica ha estado siempre unida con un recurso lexicográfico muy extendido, el de la remisión, es decir, el reenvío de una entrada a otra para conocer la definición del lema buscado a través de una marcación que indique al lector dicho procedimiento "con el objeto de relacionar las voces que presentan en la lengua algún nexo o asociación» (Morales Ruiz 1998: 5). Por lo tanto, la remisión establece relaciones formales o semánticas entre distintos elementos en el repertorio lexicográfico. De este hecho dio cuenta Rey-Debove (1989: 936):

Le système de renvois et des quasi-renvois constitue une véritable organisation de description lexicale à partir d'une présentation alphabétique commode mais non informative (sauf par hasard, dans les dérivations suffixales). Ce système permet au lecteur de quitter une liste d'items pour pénétrer dans un réseau où toutes les entrées sont en relation (même si la densité des relations est variable dans les différentes zones du lexique). Le système des renvois est alors le métalangage des structures du lexique, qui n'est nulle part explicite dans le dictionnaire, si d'ailleurs dans aucun manuel de lexicologie.

La función de la remisión, entonces, «es la de interrelacionar la información que aparece repartida entre las diferentes entradas del diccionario" (Morales Ruiz

* Esta investigación ha sido posible gracias a la ayuda otorgada por el Ministerio de Economía y Competitividad (n. ${ }^{\circ}$ de referencia FFI2014-51904-P) y al apoyo de la Generalitat de Catalunya (SGR2017-1251). 
1998: 6). En los casos en que la remisión establece una relación semántica entre el lema y la voz de la definición, las palabras implicadas son sinónimas, lo que asocia la remisión con la definición sinonímica. Solamente se diferencian porque la remisión se establece mediante el uso de un formato tipográfico distinto al utilizado en el resto del artículo. En opinión de Morales Ruiz (1998: 15), únicamente estas remisiones son una forma de definición en el diccionario.

Partiendo de estos postulados, en este estudio se da cuenta de la relación entre la definición sinonímica y la remisión en el diccionario académico, así como de las modificaciones que experimentan las definiciones sinonímicas en la sexta edición del Diccionario de la lengua castellana de la Real Academia Española (1822). Para ello, en primer lugar, se trata la remisión, sus funciones y el formato que ha adoptado en la tradición lexicográfica académica desde la primera edición del Diccionario de autoridades hasta la edición publicada en 1822 del Diccionario usual $(\$ 2)$, en segundo lugar, se explica la metodología empleada para la realización del estudio $(\$ 3)$, y, por último, se exponen las modificaciones que se han llevado a cabo en las definiciones sinonímicas en la sexta edición del Diccionario usual (1822) (\$4).

\section{LA REMISIÓN COMO RECURSO LEXICOGRÁFICO EN EL DICCIONARIO ACADÉMICO}

Desde el Diccionario de autoridades (1726-1739), los académicos utilizaron la remisión como un recurso lexicográfico que aparecía en la definición de ciertas voces. Con este procedimiento se ahorraba espacio en el diccionario, cuestión que preocupaba a menudo a la institución, puesto que indicaba que la información de un lema se hallaba en otro lema al que se remitía, «evitando repetir, de manera redundante, una misma información en dos entradas diferentes» (Morales Ruiz 1998: 13). Desde ese momento, la remisión se ha usado con diferentes finalidades $(\$ 2.1$.) y ha ido adoptando diversos formatos en la tradición lexicográfica académica $(\$ 2.2$.).

\subsection{Uso DE LA REMISIÓN}

En la planta del Diccionario de autoridades se indicó que la remisión se utilizaría para registrar en el repertorio las distintas variantes formales de una misma voz. De este modo, la remisión establecía relaciones de carácter formal entre las palabras:

Annotar las variedades que se hallaren en el escribir algunas Voces, aprobando la mejor y desechando las demás: como algunos dicen aóra, otros agóra, y parece lo mejor decir ahóra, advirtiéndolo en los lugáres que les tocáre. [...]. Mas juntamente (atendiendo à excusar la confusion en los Lectóres del Diccionario, que ignoraren de donde las Voces se origínan, y las huvieren de buscar) se annotarán segun el uso común, ò vulgar de escribirlas, en el lugar que les tocare del Alphabéto, pero remitiéndolas para su explicacion al que deben tener segun su orígen y Etymología: [...] Bolver. Vease Volver (Diccionario de autoridades 1726: XvI). 
No obstante, a pesar de que no apareciese en la planta, en esta primera edición no solamente se utilizaron las remisiones para establecer relaciones formales entre las voces, sino también para establecer relaciones semánticas de sinonimia: «BORRAX. Vease Atincar»; "GALICO. Vease Bubas». De este uso se dio cuenta en el prólogo de la segunda edición del Diccionario de autoridades (1770):

Si una cosa tiene distintos nombres, se pone la definicion en el que es actualmente de mas comun uso, y los demás se remiten á este: y quando son de igual uso, se pone en el nombre que viene primero segun el órden alfabético (Diccionario de autoridades $1770: \mathrm{VI})$.

Así pues, ya desde el Diccionario de autoridades la remisión tiene una doble función especificada por los propios académicos en los prólogos de las dos primeras ediciones de este diccionario: señalar las variantes ortográficas o morfológicas de una misma palabra (remisión formal) y mostrar las distintas voces con el mismo o semejante significado (remisión sinonímica).

En el Diccionario usual, versión del Diccionario de autoridades reducida a un tomo y publicada por primera vez en 1780, la remisión conservó las mismas funciones de uso que tenía anteriormente. En este diccionario, la remisión podía establecer A) relaciones formales de variación ortográfica (de alconero a halconero, de abahar a avahar) o morfológica, es decir, entre voces pertenecientes a una misma familia léxica pero con distinto morfema derivativo ${ }^{1}$ (de compendizar a compendiar, de obligativo, va a obligatorio, ria, de ofendedor a ofensor) y B) relaciones semánticas de sinonimia (de izquierda a siniestra, de salguera a mimbrera), las cuales se pueden dar, según la propia información que se ofrece en el diccionario, entre sinónimos intercambiables en todos los contextos de uso, es decir, que no incluyen ninguna marca restrictiva ${ }^{2}$ (de rufianear a alcahuetear, de sacatapón a sacacorchos) o entre sinónimos con restricciones ${ }^{3}$, ya sean diafásicas (de antiparras fam. a anteojos), diacrónicas (de complixionado ant. a organizado), diatópicas (de espernible p. de And. a despreciable) o diatécnicas (de sublingual Anat. a ranina). La sinonimia también es parcial o con restricciones cuando el significado del lema solamente coincide en una parte de las acepciones con la remisión (véase cubilla). Como bien se ha señalado en Jiménez Ríos (2001: 213), «que una voz remita a otra no quiere decir que esas voces sean intercambiables en cualquier contexto». De hecho, la mayoría de equivalentes poseen connotaciones que hacen que la sinonimia no sea completa, por pertenecer a otra variedad de la lengua.

Cuando la remisión establecía relaciones formales (ortográficas o morfológicas) entre las palabras, solamente aparecía una voz en la definición, la cual estaba marcada tipográficamente ( ALCON. V. HALCON»), y que era la forma recomendada

\footnotetext{
${ }^{1}$ Al ser la morfología derivativa un proceso de creación de nuevas palabras, la variación morfológica se podría incluir también dentro de las relaciones semánticas.

2 Sinonimia conceptual o total.

3 Sinonimia contextual o parcial.
} 
por la Academia y en la que se debía buscar la explicación del significado del lema. En cambio, cuando la remisión establecía relaciones semánticas de sinonimia, esta podía ser simple ("GALAMERO, RA. adj. Lo mismo que GOLOSO») o múltiple («GRATIS. adv. m. Lo mismo que DE GRACIA, Ó DE BALDE»), hecho que, como se podrá comprobar en el análisis posterior $(\$ 4$.), cambiará en la sexta edición del diccionario académico.

Además, a partir de la cuarta edición del diccionario (1803), y como consecuencia de la revisión que se llevó a cabo en este tipo de definiciones ${ }^{4}$, se añade al sinónimo una paráfrasis que sigue a la remisión, cuya utilidad es señalar la acepción concreta a la que se refiere cuando la entrada tiene varias. Esta paráfrasis no existía en las ediciones anteriores a la cuarta. Como se puede observar en la definición de la voz cubilla, en la tercera edición (1791) la información es incompleta para el usuario, puesto que no se indica a qué acepción de la entrada cubillo se refiere la remisión.

CUBILLA. s. f. Lo mismo que cubillo.

CUBILLO. s. m. d. de cubo. 2. Cantárida, ó especie de insecto ponzońoso. 3. El aposento pequeńo que hayá cada lado del teatro de comedias en Madrid, arrimado al foro debaxo de los principales (DRAE 1791).

CUBILLA. s. f. Lo mismo que cubiLlo, por el insecto llamado cantárida 5 .

CUBILLO, TO. s. m. d. de сиво.

Cubillo. Cantárida, ó abadejo, especie de insecto ponzoñoso.

Cubillo. El aposento pequeño que hayá cada lado del teatro de comedias en Madrid, arrimado al foro debaxo de los principales (DRAE 1803).

Esta formulación se mantuvo hasta la duodécima edición del diccionario (1884) en la que la paráfrasis se cambió por el número de la acepción:

Cubilla. f. Cubillo, $1 .^{a}$ acep.

Cubillo. (d. de cubo) m. Cantarida, $1 .^{a}$ acep. \|Pieza de vajilla para mantener fría el agua. \|Aposento pequeńo que había á cada lado de la embocadura en los teatros de Madrid, debajo de los palcos principales.

Esta modificación supone un doble esfuerzo para el lexicógrafo, puesto que en cada nueva edición se debe revisar si ha cambiado el orden de los significados por haber incluido o suprimido alguna acepción.

${ }^{4}$ En el prólogo de la cuarta edición del diccionario académico se señala que «despues de impreso todo el Diccionario, le ha vuelto á reconocer y leer enteramente con el objeto de comprobar las remisiones, y de observar si estaban en su debido lugar algunas de las voces usadas en las definiciones de diferentes artículos» (DRAE 1803: prólogo).

${ }^{5}$ En las citas la negrita es nuestra. 


\subsection{ForMATO DE LA REMisióN}

Ya en la redacción del primer diccionario los académicos decidieron establecer un sistema para reconocer las remisiones. En el Acta del 10 de mayo de 1731 se acordó que se utilizarían fórmulas de enlace cuando la «explicacion [de una voz] se reduce solo a la comparación con otra voz que es univoca o synonima con aquella de que se trata» (cfr. Carriscondo Esquivel 2009:126). Asimismo, aunque en un principio no se explicitó en los distintos documentos redactados por los académicos, además de las fórmulas de enlace también se utilizó una marca tipográfica, la mayúscula inicial, con el objetivo de distinguir la voz en la que se debía buscar la definición del lema consultado. No obstante, hasta la primera edición del Diccionario usual (1780) no se acordó el uso de la versalita como marca tipográfica, la cual se mantuvo hasta la undécima edición del diccionario (1869).

En la primera edición del Diccionario de autoridades (1726-1739) la remisión se reconocía por el empleo de la fórmula de enlace véase, que podía preceder o seguir a la equivalencia. Este último caso se daba cuando la definición estaba encabezada por otras fórmulas como, por ejemplo, lo mismo que (alcazuz) o lo propio que (baxo [11]).

ALCONERA. Vease Halconera.

ALCAZUZ. Lo mismo que Alcazcúz. Vease.

BAXo[11]. adv. Lo própio que Abaxo. Vease.

Además, como se puede observar en los ejemplos anteriores (alconera, alca$z u z$ y baxo [11]), en ocasiones, también se podía utilizar la mayúscula inicial como marca tipográfica para señalar la equivalencia, aunque su uso no se puso en práctica en el diccionario de manera sistemática, ni cuando la remisión establecía relaciones formales entre las palabras ("AHASTA. adv. Lo mismo que hasta. Vease. Voz antiquada»), ni cuando expresaba relaciones semánticas («CORVO [2]. Lo mismo que garfio»).

En la segunda edición del Diccionario de autoridades (1770), el formato de la remisión continuaba siendo igual que en la primera edición, aunque, como ha observado Pascual Fernández (2019), con un claro predominio del uso de la fórmula lo mismo que $e^{6}$ para remitir tanto a variantes formales ("ABAXAR. v. n. antiq. Lo mismo que baxar») como a sinónimos (BLASMO. s. m. antiq. Lo mismo que desdoro, vituperio) ${ }^{7}$. Además, en esta segunda edición, a diferencia de lo comentado para la anterior, se evitó utilizar más de una fórmula de enlace en una misma definición:

${ }^{6}$ Los datos obtenidos por Pascual Fernández (2019) en el análisis del primer tomo de la segunda edición del Diccionario de autoridades que comprende las letras A y B son los siguientes: 466 remisiones con $V$. y 1960 remisiones con lo mismo que.

7 Según los datos de Pascual Fernández (2019), en las Reglas para la corrección del diccionario de 1743 «se advierte que las variantes originadas por dialecto antiguo, provincial o por uso común se señalen con véase y las voces sinónimas se destaquen con lo mismo que». No obstante, en 
BAXo [11]. adv. Lo própio que Abaxo. Vease (Diccionario de autoridades 1726: s. v. baxo).

BAXo [11]. adv. Lo mismo que Abaxo (Diccionario de autoridades 1770: s. v. baxo).

Posteriormente, en la primera edición del Diccionario usual (1780) se determinó que se usaría la letra versalita para expresar la remisión, además de para otras funciones como señalar el infinitivo en las definiciones de los participios («ACOBARDADO, DA. p. p. de ACOBARDAR») y marcar el sustantivo o el adjetivo en las definiciones de los diminutivos, aumentativos y superlativos ("CASCARILLA, CASCARITA. s. f. d. de CÁsCARA»). De estos usos se da cuenta en el prólogo de la séptima edición del diccionario (1832):

Es preciso advertir que no todo lo que aparezca en versalitas es en rigor verdadera remisión, sino solo indicacion de equivalencia de voces ó frases. Así no extrañará el lector que siendo equivalentes varios adjetivos á participios, en algunos nombres vulgares a nombres propios y otros vocablos á locuciones compuestas de dos ó mas de ellos, se hayan impreso las equivalencias en versalitas para proceder de un modo uniforme en todo el Diccionario (DRAE 1832: prólogo).

La letra versalita, por lo tanto, se concibió como un recurso lexicográfico usado con distintos fines que se mantuvo en el diccionario académico hasta la undécima edición (1869). En la edición posterior (1884), y hasta la actualidad (2014), la versalita se cambió por la negrita.

Por lo que respecta a las fórmulas que encabezan las definiciones por remisión, en las ediciones publicadas en 1780, 1783 y 1791 continuaron siendo las mismas que en el Diccionario de autoridades - $V$. o lo mismo que - hasta la cuarta edición (1803) en la que se redujeron a una sola -lo mismo que- ${ }^{8}$. No obstante, se continuó utilizando la abreviatura $V$. "para enviar a la entrada que desarrolla la definición en las formas complejas» (Pascual Fernández, 2019). En la sexta edición (1822) la fórmula lo mismo que se suprimió definitivamente, tanto en las definiciones en las que la remisión establecía una relación formal como en las que establecía una relación de sinonimia.

ROMANZAR. Vease Romancear (Diccionario de autoridades 1737)

ROMANZAR. V. ROMANCEAR (DRAE 1780-1791)

ROMANZAR. Lo mismo que ROMANCEAR (DRAE 1803-1817)

ROMANZAR. ROMANCEAR (DRAE 1822-1869).

las Reglas posteriores (1757, 1764 y 1770) esta precisión se cambia a favor de la fórmula lo mismo que: «En los sinónimos o voces equivalentes se pondrá la definición en la que tuviere mas uso, y las demás se remitirán diciendo: tal cosa, lo mismo que tal cosa» (Reglas 1770: 39-40).

${ }^{8}$ A pesar de que la reducción a una única fórmula se llevó a cabo de manera sistemática, en algunas definiciones como la de satanás se mantiene hasta la quinta edición: «Nombre que comunmente significa el enemigo común ó el demonio, aunque en su rigurosa significación vale lo mismo que CONTRADICTOR Ó ADVERSARIO" (DRAE 1817: s. v. satanás). 
Igualmente, como se indicó en el prólogo, también se eliminaron expresiones y fórmulas de enlace de las definiciones perifrásticas, como, por ejemplo, que es como mas comunmente se dice, que es mas usado, que llamamos, que también se llama:

Ha omitido [la Academia] en las voces sinónimas ó de un significado ${ }^{9}$ la fórmula Lo mismo que, poniendo en versalillas la voz correspondiente mas castiza ó de un uso mas general, por ejemplo Alfabeto s. m. Abecedario, Ebriedad s. f. Embriaguez, Mote s. m. Apodo. Igual economía ha tenido en las expresiones: que es como mas comunmente se dice; que es mas usado, que se usa mas frecuentemente; $y$ otras semejantes; pues solo la remision de una voz á otra, que está definida, basta para indicar que esta es la mas propia y de un uso mas comun y constante (DRAE 1822: prólogo).

Son algunos ejemplos las definiciones de los vocablos ajuagas, arreglamiento, asombradizo, arrepticio, borron [2], mojon [2], natas [3], naterón o zara. En ocasiones, como en mojon y zara, el empleo de estas fórmulas supone la introducción de variantes léxicas en la explicación, por lo que algunas de estas definiciones perifrásticas en la sexta edición se cambiaron a definiciones sinonímicas por remisión.

\begin{tabular}{ll}
\hline \multicolumn{2}{c}{ TABLA 1 } \\
\hline \multicolumn{2}{c}{ DRAE 1817 } \\
\hline Mojon [2]. Especie de juego que también se llama tangano. & DRAE 1822 \\
\hline ZARA. s. f. El trigo de las Indias que llamamos maíz. & ZARA. s. f. MAíz. \\
\hline
\end{tabular}

Resumiendo, se puede decir que en el Diccionario de autoridades se intentó fijar un método para el empleo y reconocimiento de la remisión, el cual, en la primera edición del Diccionario usual, se hizo explícito con el uso de la versalita como marca tipográfica. A partir de esa edición, la revisión de este tipo de definiciones fue continua, así aparece indicado en los prólogos, delimitando cada vez más la técnica lexicográfica. No obstante, en las cinco ediciones que llegan hasta la de 1817 existe una coincidencia en la manera de tratar las definiciones sinonímicas con remisión y las definiciones sinonímicas sin remisión -en ambos casos la definición puede estar formada por uno o más de un sinónimo, los sinónimos se hallan introducidos por una fórmula de enlace y aparecen marcados tipográficamente con la versalita-, hecho que, como se podrá comprobar en el análisis posterior, cambiará en la sexta edición del diccionario académico.

\footnotetext{
9 El uso de esta expresión reafirma la idea de que todas las definiciones sinonímicas de un sinónimo o de un significado son remisiones.
} 


\section{METODOLOGÍA}

Para obtener los datos sobre los que se ha desarrollado el presente estudio, se ha llevado a cabo un cotejo entre la sexta edición del diccionario académico (1822) y su edición precedente (1817). Para ello, se han elegido 20 páginas al azar de la edición de 1822 según la técnica de muestreo estratificado, es decir, asegurando que estuviesen presentes en el corpus la mayoría de letras (2 páginas de las letras $A$ y $C$, por ser estas letras mucho más extensas que las otras, y 1 página de las letras $B, D$, $E, F, G, H, I, M, P, R, S, T, V$ у $Z$ ).

Posteriormente, se han vuelto a cotejar 10 páginas más como corpus de control (1 página seleccionada al azar de las letras $B, D, F, L, M, N, O, P, R$ y $S$ ), las cuales han dado como resultado los mismos tipos de cambios que aparecieron en el primer cotejo. Por ello, se puede pensar que, a pesar del bajo tanto por ciento de la muestra, el margen de error es admisible para apuntar tendencias e inferir resultados.

Finalmente, además de estas páginas cotejadas enteramente, siempre que ha sido necesario se han indagado casos determinados con búsquedas dirigidas. Por ejemplo, para el caso concreto de las remisiones en las voces de germanía, se han cotejado todas las páginas de las letras $A$ y $B$.

Los resultados obtenidos en el cotejo se han organizado en una tabla en la que consta el lema de la edición de 1822 que experimenta algún cambio respecto a la edición precedente (1817), el tipo de modificación y el texto que cambia con algún comentario, si era el caso.

\section{LAS DEFINICIONES SINONÍMICAS \\ EN LA SEXTA EDICIÓN DEL DICCIONARIO ACADÉMICO}

En la sexta edición del diccionario de la Academia la manera de proceder en el tratamiento y la formalización de la definición sinonímica cambiará sustancialmente respecto de las ediciones anteriores, puesto que, a diferencia de ellas, la versalita se empezará a utilizar solamente en las definiciones sinonímicas constituidas por una única palabra («TROTACONVENTOS. s. f. fam. ALCAHUETA»). En las definiciones formadas por más de una voz, es decir, en las sinonímicas múltiples ${ }^{10}$, la tipografía será la misma que en el resto del artículo: la redonda («FRESAR. v. n. ant. Gruñir ó regañar», «LUCENCIA. s. f. ant. Claridad, resplandor, luz»).

Por ello, una parte de las modificaciones que se llevaron a cabo en la sexta edición del diccionario están orientadas a cambiar la tipografía en las definiciones sinonímicas simples y múltiples y en las definiciones perifrásticas (\$ 4.1.). Las otras modificaciones se realizaron en las definiciones sinonímicas por remisión, ya sea porque se intentó evitar las cadenas no formalizadas en el diccionario (\$ 4.2.) -una

10 Porto Dapena (2002: 288), para las definiciones sinonímicas formadas por más de un sinónimo, utiliza los términos definición compleja o acumulativa. 
cuestión que ha preocupado siempre a la institución, puesto que en todos los prólogos de las distintas ediciones del diccionario se hace mención a ello-, porque cambió la variante léxica preferida por la Academia (\$4.3.), porque dos palabras tenían el mismo significado en la edición anterior publicada en 1817 ( $\$ 4.4$.) o porque se corrigieron algunos errores que aparecían en el diccionario (\$ 4.5.).

\subsection{Cambios En la tipografía}

En la sexta edición del diccionario académico se pretende fijar el uso de la versalita en los casos de definición sinonímica dependiendo de si esta es de un solo sinónimo, de diversos sinónimos o perifrástica. Por ello, se producen bastantes cambios entre esta tipografía y la redonda y viceversa motivados por el ejercicio de la aplicación de una normativa al respecto.

En las definiciones sinonímicas simples se utiliza la versalita, lo que conlleva que sinónimos que en la edición anterior estaban en redonda pasen a estar en versalita, es decir, aquellas definiciones formadas por una única voz, cuando esta aparece en redonda en la quinta edición del diccionario académico, como en volver [12], y en aquellos casos que se reduce a uno el número de sinónimos de la definición, como en tendal [2].

\begin{tabular}{|c|c|}
\hline \multicolumn{2}{|c|}{ TABLA 2} \\
\hline DRAE 1817 & $D R A E 1822$ \\
\hline VOLVER [12]. Vomitar. & Volver [12]. Vomitar. \\
\hline $\begin{array}{l}\text { Tendal [2]. En algunas partes lo mismo que el tendedero } \\
\text { ó tendalero. }\end{array}$ & Tendal [2]. En algunas partes TENDEDero. \\
\hline
\end{tabular}

Siguiendo este criterio, se mantiene la versalita en aquellas entradas en las que se pasa de una definición perifrástica a una definición sinonímica (lopicia) de un solo equivalente y en aquellas en las que se cambia de una definición sinonímica múltiple -grafiados en versalita los distintos equivalentes-a una definición sinonímica simple (camiar, frisuelo).

\begin{tabular}{|c|c|}
\hline \multicolumn{2}{|l|}{ TABLA 3} \\
\hline$D R A E 1817$ & $D R A E 1822$ \\
\hline $\begin{array}{l}\text { LOPICIA. s. f. Lo mismo que ALOPECIA ó peladera, enfermedad } \\
\text { que hace caer los cabellos. }\end{array}$ & LOPICIA. s. f. ALOPECIA. \\
\hline CAMIAR. v. a. ant. Lo mismo que CAMBIAR, TROCAR, MUDAR. & CAMIAR. v. a. ant. CAMBIAR. \\
\hline $\begin{array}{l}\text { FRISUELO. s. m. En algunas partes lo mismo que FRísol o } \\
\text { JUDIHUELO. }\end{array}$ & FRISUELO. s. m. En algunas partes FRÍsOL. \\
\hline
\end{tabular}

En cambio, siguiendo las directrices dadas, se utiliza la redonda en las definiciones perifrásticas. Ello implica el cambio de tipografía, de versalita a redonda, 
en las definiciones perifrásticas en las que se utilizaba la versalita seguida de una explicación.

\section{TABLA 4}

DRAE 1817

DRAE 1822

Rueda [7]. Lo mismo que tontillo de lana ó cerdas que se pone en los pliegues de las casacas de los hombres para que se ahuequen y paren firmes.

Rueda [7]. Especie de tontillo de lana ó cerdas que se ponía en los pliegues de las casacas de los hombres para ahuecarlas y mantenerlas firmes.

Asimismo, también se utiliza la redonda en las definiciones sinonímicas múltiples. Por ello, se ha modificado la tipografía de muchas entradas, como en absolver [2], dilación [2], de barra a barra (s. v. barra), callandico, cela [2], cejo [2], competencia [2], compiadarse, complanar, complimiento [1], componimiento [2, 3, 4], comportarse, delibranza, desraspar, destajo [2], destemperado, difamia, diferecer, duro [2], friera, fresar, frescor, fronda, de fuerza (s. v. fuerza), fuidizo, fuimiento, fundo [2], lucencia, bueno pecho (s. v. pecho) y zarrapastra.

\begin{tabular}{|c|c|}
\hline \multicolumn{2}{|c|}{ TABLA 5} \\
\hline$D R A E 1817$ & $D R A E 1822$ \\
\hline $\begin{array}{l}\text { ABSOLVER [2]. ant. Lo mismo que RESOLVER, DECLA- } \\
\text { RAR, DESCIFRAR, DAR SOLUCION. }\end{array}$ & $\begin{array}{l}\text { ABSOLVER [2]. ant. Resolver, declarar, descifrar, dar } \\
\text { solucion. }\end{array}$ \\
\hline $\begin{array}{l}\text { DILACION [2]. ant. Lo mismo que DILATACION, EX- } \\
\text { TENSION, PROPAGACION. }\end{array}$ & DILACION [2]. ant. Dilatacion, extension, propagacion. \\
\hline
\end{tabular}

En los datos cotejados se encuentran algunos casos en que este cambio de versalita a redonda no se ha experimentado, como, por ejemplo, en cambra, callizo y jacer, en los que la modificación se realizará en la edición de $1884^{11}$, lo que induce a pensar que se trata de olvidos que fueron subsanados posteriormente.

Se observa, pues, que en esta edición se pretende eliminar el uso de la versalita en las definiciones perifrásticas (rueda [7]), y en las definiciones sinonímicas múltiples con remisión (absolver [2], dilacion); en cambio, se procura usar la versalita en las definiciones sinonímicas simples (volver [12]). Esta tendencia se reafirma cuando se analizan las voces de nueva incorporación de la edición de 1822 cuya defi-

11 La definición de las tres excepciones se modifica en la duodécima edición: en callizo se divide la remisión múltiple en dos acepciones: "CALLIZO. m. pr. Ar. CALlejón ó Callejula» (DRAE 1869) > "Callizo. m. pr. Ar. Callejón // pr. Ar. Callejula» (DRAE 1884); en cambra se elimina una de las voces que aparecen en la definición: "CAMBRA. f. ant. CÁMARA ó CUARTO» $(D R A E 1869)>$ "Cambra. f. ant. Cámara» (DRAE 1884); y en jacer se modifica el tipo de letra de versalita a redonda: «JACER. a. ant. Tirar ó ARrojAR» $(D R A E 1869)$ > «Jacer. a. ant. Tirar ó arrojar» (DRAE 1884). 
nición es sinonímica por remisión, puesto que todas están formadas por una única equivalencia grafiada en versalita ( $c f r$. Terrón, en prensa) ${ }^{12}$.

Cabe destacar que las voces pertenecientes al ámbito de la germanía presentan en todas las ediciones del Diccionario usual un comportamiento distinto al resto de vocablos ${ }^{13}$. Partiendo de los datos cotejados, se ha comprobado que siempre se utiliza la tipografía redonda en las definiciones sinonímicas, estén formadas por una voz (aires, arredomar, artifara y artife, artifero, asa [4], atalaya [3], aviso [4], avispar [3], buyes, bufiador, bosque [2], etc.) o por más de una (arrojados [3], bramar, bramo, bravote, búho [2]). Únicamente se utiliza la versalita cuando la palabra que aparece en la definición también pertenece al ámbito de la germanía, como en bellosa y birloche:

BELLOSA. s. f. Germ. BEDILLA.

BEDILLA. s. f. Germ. La frezada.

BIRLOCHE. s. m. BIRLESCO.

BIRLESCO. s. m. Germ. Ladron y rufian.

Los cambios que se llevan a cabo en la tipografía en la sexta edición parecen indicar que solamente las definiciones sinonímicas simples pueden constituir remisiones: $(A=b)=(A=B)$, puesto que los sinónimos que aparecen en las definiciones sinonímicas múltiples difícilmente pueden compartir todos o la mayoría de los rasgos definitorios con el lema: $A=(b \approx c \approx d)$.

\subsection{CorRección de las CADENAS NO FORMALIZADAS}

Además de las modificaciones en la tipografía, en la sexta edición se continuó con las directrices que se habían indicado en el prólogo de la edición anterior y que se repetían en esta:

Se ha procurado con esmero rectificar las remisiones de las voces sinónimas ó equivalentes ${ }^{14}$, sobre cuyo punto se había notado alguna negligencia en las anteriores ediciones. En la actual se ha corregido este defecto, cotejando escrupulosamente los artículos de remisiones con aquellos á que se remiten como principales, y que alguna vez solían echarse menos (DRAE 1817: prólogo).

12 En el estudio de Muñoz (2018: 214-216) se ha comprobado que en las voces de nueva incorporación de la edición de 1817 se incluyen un total de 323 definiciones sinonímicas por remisión y solamente 12 incluyen más de una equivalencia. Esto parece indicar que la tendencia en la quinta edición ya era evitar el uso de la remisión múltiple $(\mathrm{A}=\mathrm{B}, \mathrm{C})$.

${ }^{13}$ Las definiciones de las voces de germanía han sido tratadas de manera distinta al resto de vocablos en todas las ediciones del Diccionario usual. No solamente se diferencian en el modo de tratar la equivalencia, sino que también, como observó Alvar Ezquerra (1983: 215), su definición carece de correspondencia latina.

${ }^{14}$ En el prólogo de la sexta edición solamente aparece la parte marcada en negrita. 
Se intenta evitar en el diccionario lo que actualmente se denominan cadenas no formalizadas, utilizando la terminología de Castillo Peña (1992-1993), es decir, aquellas que presentan errores de diverso tipo, ya sea porque la equivalencia no se encuentra en el lemario formando una cadena perdida o porque ambas palabras (el lema y la equivalencia) se remiten entre sí creando un círculo vicioso. En este sentido, las definiciones sinonímicas simples no suelen presentar errores de ningún tipo. En opinión de Castillo Peña (1993: 204), es más común hallar incoherencias en las definiciones sinonímicas formadas por más de una voz (múltiples). No obstante, se han detectado algunos casos incorrectos en las definiciones sinonímicas simples, los cuales se corrigen en la sexta edición.

\begin{tabular}{|c|c|}
\hline \multicolumn{2}{|r|}{ TABLA 6} \\
\hline DRAE 1817 & DRAE 1822 \\
\hline ATINCAR. s. m. Lo mismo que BORRAX. & ATINCAR. s. m. BORRAX. \\
\hline BORRAX. s. m. Lo mismo que ATINCAR. & $\begin{array}{l}\text { BORRAX. s. m. Sal blanca por afuera y cristalina por dentro, } \\
\text { que se encuentra naturalmente formada en las aguas de diferentes } \\
\text { lagos, especialmente de las Indias Orientales, de donde se saca } \\
\text { y purifica. Es medicinal y se emplea en las artes para soldar el } \\
\text { oro, la plata y otros usos. }\end{array}$ \\
\hline FUGA. s. f. Lo mismo que HUIDA. & FUGA. s. f. HUIDA APRESURADA ${ }^{1}$. \\
\hline HUIDA. s. f. Lo mismo que FUGA. & HUIDA. s. f. FUGA. \\
\hline Ábrigo [4]. ant. Lo mismo que sUdoeste. & ÁBRIGO [4]. ÁBREGO. \\
\hline [SUDOESTE no aparece como lema]. & ABREGO. s. m. Viento que sopla entre mediodía y poniente. \\
\hline
\end{tabular}

${ }^{1}$ El uso de la versalita en lugar de la redonda en la palabra apresurada es un error que se corrige en la edición siguiente de 1832.

Como se puede observar en la tabla 6, atincar y borrax formaban en la edición de 1817 un círculo vicioso que se deshizo en la edición posterior de 1822. Este círculo proviene de la quinta edición, ya que en las ediciones anteriores la voz atincar aparecía definida y en la parte final de la explicación se especificaba lo siguiente: «llámase en las boticas borrax». En las voces huida y fuga se ha deshecho el círculo definiendo este último término. En el caso de ábrigo, la incoherencia estriba en que la equivalencia no aparece en la macroestructura de la quinta edición, puesto que la voz sudoeste se registró por primera vez en 1822. Por lo tanto, a partir de la revisión de este lema en la quinta edición, en la sexta se intentó deshacer la cadena perdida de dos formas: incluyendo sudoeste en el lemario de 1822 y cambiando la remisión de sudoeste a ábrego, como ya estaba en las ediciones anteriores a la quinta (17801803), edición en la que se generó el error.

Cabe destacar que en las setenta y dos voces de nueva incorporación en las que su definición consta de una remisión solamente una de ellas remite a un lema que no se encuentra en el lemario. Este es el caso de chiquilicuatro, en cuya definición aparece chisgarabis, voz que no se incorporó en el diccionario hasta la octava edición, por lo que la cadena perdida no se enmendó hasta 1837. 
En algunos casos la modificación en el redactado de las definiciones está motivada porque se produce un cambio en la elección de la variante léxica preferida, como en voltereta o en tendal [3]:

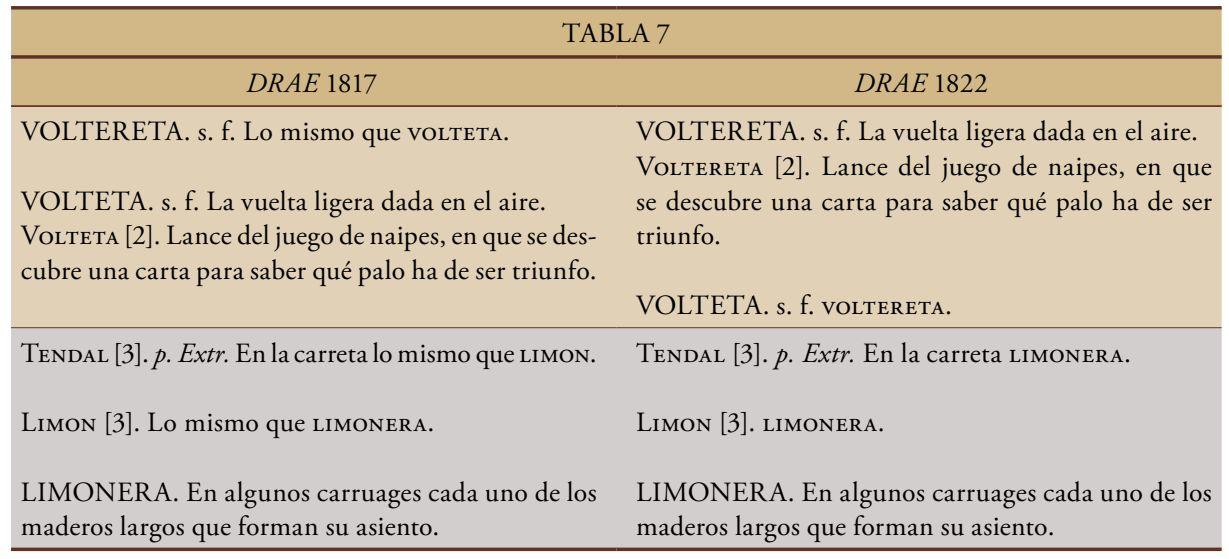

En el caso de voltereta, a partir de la edición de 1822, como ya se había acordado en la segunda edición del Diccionario de autoridades (1770: prólogo), la variante preferida por la Academia es voltereta por ser de "mas comun uso», ya que es la voz definida. No obstante, en el Diccionario castellano de Terreros y Pando de 1788 el término preferido ya era voltereta. Se ha realizado una búsqueda de las palabras volteta y voltereta entre 1800 y 1822 en Ngram Viewer ${ }^{15}$ y se ha observado un cambio de preferencia de volteta a voltereta a partir de 1825 , justamente el año en el que la voz voltereta empieza a documentarse en el CORDE.

En cuanto al término tendal [2], la remisión cambia de limón a limonera porque esta última es la variante preferida tanto en 1817 como en 1822. En ambas ediciones, la acepción de limón que se refiere a tendal [2] remite a limonera y esta es la que aparece definida en el diccionario. Por lo tanto, en la edición de 1822 se disminuye la cadena de remisión eliminando una etapa intermedia (1817: tendal $\rightarrow$ limón $\rightarrow$ limonera $>$ 1822: tendal $\rightarrow$ limonera).

15 El programa Google Ngram Viewer o Google Books Ngram Viewer (https://books.google. $\mathrm{com} /$ ngrams/) es un motor de búsqueda en línea que ofrece, en forma de gráfico, las frecuencias de cualquier conjunto de cadenas de palabras utilizando un recuento anual de n-gramas encontrados en fuentes impresas entre 1500 y 2008 en los textos de Google corpora. El programa permite delimitar la lengua de análisis y el marco temporal. 


\subsection{CAMBIOS ENTRE DEFINICIONES PERIFRÁSTICAS Y SINONÍMICAS}

Otra de las enmiendas que se han detectado en la edición de 1822 es el cambio de una definición perifrástica a una sinonímica por remisión en las voces que tenían la misma definición en la quinta edición. Este procedimiento está relacionado con los objetivos reductores que guiaron la redacción de la sexta edición, ya que el lexicógrafo ahorra espacio en la microestructura omitiendo una definición. Son ejemplos de ello las voces tenacicas [2], pechero [2], mogrollo, abrigano, mojonero, penitenciero mayor (s. v. penitenciero), y sarrillo:

\begin{tabular}{|c|c|}
\hline \multicolumn{2}{|c|}{ TABLA 8} \\
\hline DRAE 1817 & $D R A E 1822$ \\
\hline $\begin{array}{l}\text { DESPABILADERAS. s. f. p. Las tijeras con que se } \\
\text { despabila. }\end{array}$ & $\begin{array}{l}\text { DESPABILADERAS. s. f. p. Las tijeras con que se } \\
\text { despabila. }\end{array}$ \\
\hline $\begin{array}{l}\text { Tenacicas [2]. Las tijeras con que se corta el pábilo } \\
\text { de la vela. }\end{array}$ & Tenacicas [2]. Despabiladeras. \\
\hline $\begin{array}{l}\text { BABADOR. s. m. Pedazo de lienzo, que para mas } \\
\text { limpieza ponen á los nińos en el pecho. }\end{array}$ & $\begin{array}{l}\text { BABADOR. s. m. Pedazo de lienzo que para mas } \\
\text { limpieza ponen á los niños en el pecho. }\end{array}$ \\
\hline $\begin{array}{l}\text { Pechero [2]. s. m. El lienzo ó pańo que se suele poner } \\
\text { á los niños en el pecho para que no manchen la ropa. }\end{array}$ & Pechero [2]. s. m. Babador. \\
\hline $\begin{array}{l}\text { GORRISTA. s. m. El que frecuentemente come á } \\
\text { costa ajena. }\end{array}$ & $\begin{array}{l}\text { GORRISTA. s. m. El que frecuentemente come á } \\
\text { costa ajena. }\end{array}$ \\
\hline MOGROLLO. s. m. El que come a costa agena. & MOGROLLO. s. m. Gorrista. \\
\hline
\end{tabular}

En estos casos, tanto la entrada que tiene la definición como la que tiene la remisión parecen ser de igual uso, puesto que ninguna de las voces lleva marcas que lo restrinjan. En estas ocasiones, al considerar que ambos lemas son de uso común, como ya se indicó en el prólogo del Diccionario de autoridades, para incluir la definición se eligió el lema que va primero según el orden alfabético.

\subsection{CORRECCIÓN DE ERRORES}

Finalmente, en la sexta edición del diccionario también se corrigieron algunos errores en las definiciones sinonímicas por remisión. Este es el caso de lua, en la que se cambió la definición sinonímica por una perifrástica, puesto que el lema y la equivalencia (lua y guante) no comparten plenamente el mismo significado. Por lo tanto, en la edición de 1822, al término lua se le añaden las características particulares que lo diferencian de guante. En lóndiga se ha corregido la remisión debido a que el término alóndiga no aparece registrado en ninguna edición del diccionario académico. 
TABLA 9

$D R A E 1817$

LUA. s. f. ant. Lo mismo que GUANTE.
DRAE 1822

LUA. s. f. ant. Especie de guante hecho de esparto y sin separación para los dedos, el cual sirve para limpiar a las caballerías.

En el vocablo sartal, en cambio, la modificación se realiza en la explicación que aparece seguida de la remisión, la cual apunta a una acepción del artículo encabezado por el lema sarta:

\section{TABLA 10}

\section{DRAE 1817}

SARTAL. s. m. Lo mismo que SARTA por el conjunto de cosas ensartadas.

SARTA. s. f. La composicion de cosas metidas por órden en un hilo, cuerda ú otra cosa.

SARTA. La porción de cosas ensartadas.

SARTA. met. La union por órden seguida que llevan unas cosas con otras.

\section{DRAE 1822}

SARTAL. s. m. SARTA por la porción \&c.

SARTA. s. f. La composicion de cosas metidas por órden en un hilo, cuerda ú otra cosa.

SARTA. La porción de cosas ensartadas.

SARTA. met. La union por órden seguida que llevan unas cosas con otras.

Como se puede observar en la tabla 10, en la voz sartal se ha corregido la perífrasis que sigue a la remisión, ya que en ninguna acepción de sarta se encuentra el término conjunto, pero sí el de porción. La segunda acepción de la voz sarta se ańadió en la edición de 1817.

\section{CONSIDERACIONES FINALES}

Desde el Diccionario de autoridades ha sido recurrente utilizar la definición sinonímica en la explicación de un vocablo. Estas definiciones podían estar formadas por una voz («АDOBO [3]. Se toma también por Adorno») o por varias voces de significados afines al lema («GRATIS. Lo mismo que De gracia ú de balde»). Como se puede observar en este último ejemplo (gratis), algunas veces, los sinónimos pueden aparecer introducidos por fórmulas como lo mismo que, lo propio que, etc.

A partir de la primera edición del diccionario académico (1780) y hasta la quinta (1817) también es posible hallar los sinónimos marcados tipográficamente con versalita e introducidos con una fórmula de enlace, tanto en las definiciones sinonímicas simples ("ADOBO [5]. ant. Lo mismo que ADORNO») como en las múltiples («FRESAR. v. n. ant. Lo mismo que GRUÑIR ó REGAÑAR», "GRATIS. Lo mismo que De GRACIA, ó DE BALDE» 0 «LUCENCIA. s. f. ant. Lo mismo que ClARIDAD, RESPLANDOR, LUZ»).

Esta manera de proceder cambió en la sexta edición del Diccionario de la lengua castellana, objeto de estudio de este trabajo. Ya en su prólogo la Academia 
hace constar dos objetivos principales: por una parte, la reducción del espacio utilizado, y por ello «acordó la supresion de algunas fórmulas y artículos que creyó podrian excusarse sin perjuicio de la claridad conveniente y con mucho ahorro de palabras» (DRAE 1822: prólogo) y, por otra parte, la revisión de las entradas sinonímicas procurando «con esmero rectificar las remisiones de las voces sinónimas o equivalentes» (DRAE 1822: prólogo).

Así pues, en lo referente al tratamiento de las entradas con definición sinonímica la Academia intentó poner orden y coherencia interviniendo especialmente en diversos aspectos:

En primer lugar, estableció una distinción entre las definiciones de un solo sinónimo (que pueden compartir rasgos definitorios al cien por cien, o casi al cien por cien) y las de más de un sinónimo (que comparten algunos rasgos definitorios, pero no en su totalidad).

En segundo lugar, hizo uso de un recurso lexicográfico, la remisión, para suprimir definiciones repetidas, indicando dónde debe buscarse la información lingüística de una voz sinonímica sin explicación. Para seleccionar la voz portadora de la definición, la Academia estipuló que se escogiera la palabra «de un uso mas comun y constante» (Diccionario de autoridades 1770: prólogo) y, en el caso de igual uso, que se eligiera la primera según el orden alfabético. Sin embargo, este recurso no se utiliza en el diccionario académico solamente para casos de remisión sinonímica, sino también para la remisión formal, reenviando a una voz principal en el caso de las variantes gráficas (de alconero a halconero) y morfológicas (de obligativo, va a obligatorio, ria).

Todo ello llevó a que en la sexta edición del diccionario académico:

- Se eliminara en las definiciones la fórmula de remisión lo mismo que manteniendo la versalita como indicación de remisión.

- Se suprimiese la versalita de las definiciones sinonímicas múltiples y se incorporara en las pocas definiciones sinonímicas simples que aparecían en redonda, excepto en las voces pertenecientes a la germanía, que, a pesar de ofrecer un solo sinónimo, solamente usan la versalita cuando se trata de enviar a otra voz también del mismo ámbito.

- Se revisaran las «cadenas perdidas» y los «círculos viciosos» que existían en las definiciones sinonímicas, cosa que se tuvo muy presente de evitar en las voces de nueva incorporación.

- Se sustituyesen algunas definiciones perifrásticas por definiciones sinonímicas por remisión en las voces que en la edición anterior repetían la misma definición.

Por todo ello, se puede afirmar que la sexta edición del diccionario académico es más coherente en la organización de las definiciones sinonímicas simples y múltiples y en el empleo de la versalita como recurso lexicográfico de remisión. 


\section{BIBLIOGRAFÍA}

Alvar Ezquerra, Manuel (1983): «Los prólogos del Diccionario académico. Nomenclatura específica y microestructura", Revista de Filología Española LXIII, 3/4: 205-222.

Ahumada Lara, Ignacio (1989): Aspectos de lexicografía teórica. Aplicaciones al Diccionario de la Real Academia Española, Granada: Universidad de Granada.

Castillo Peña, Carmen (1992): «La definición sinonímica y los círculos viciosos», Boletín de la Real Academia Española 72: 463-566.

Castillo Peña, Carmen (1993): «La definición sinonímica y los círculos viciosos (continuación)», Boletín de la Real Academia Española 73: 133-213.

Carriscondo Esquivel, Francisco Manuel (2009): «En los orígenes del método colegiado académico: el Papel de reparos al Diccionario (1731)», Bulletin Hispanique 101: 109-140.

DICCIONARIO DE AUTORIDADES = REAL ACADEMIA ESPAÑOLA (1726-1739): Diccionario de la lengua castellana, en que se explica el verdadero sentido de las voces, su naturaleza y calidad con las phrases o modos de hablar, los proverbios o refranes, y otras cosas convenientes al uso de la lengua, 6 vols., Madrid, Imprenta Francisco del Hierro.

DICCIONARIO DE AUTORIDADES = REAL ACADEMIA ESPAÑOLA (1770): Diccionario de la lengua castellana, segunda impresión corregida y aumentada, tomo primero: A-B, Madrid: Joachin Ibarra.

DRAE 1780 = REAL ACADEMIA ESPAŃOLA (1780): Diccionario de la lengua castellana, reducido a un solo tomo para su más fácil uso, Madrid: Joaquín Ibarra.

DRAE 1783 = REAL ACADEMIA ESPAÑOLA (1783): Diccionario de la lengua castellana, reducido a un solo tomo para su más fácil uso, segunda edición, Madrid: Joaquín Ibarra.

DRAE 1791 = REAL ACADEMIA ESPAÑOLA (1791): Diccionario de la lengua castellana, reducido a un solo tomo para su más fácil uso, tercera edición, Madrid: Viuda de don Joaquín Ibarra.

DRAE 1803 = REAL ACADEMIA ESPAÑOLA (1803): Diccionario de la lengua castellana, reducido a un solo tomo para su más fácil uso, cuarta edición, Madrid: Viuda de don Joaquín Ibarra.

DRAE 1817 = REAL ACADEMIA ESPAÑOLA (1817): Diccionario de la lengua castellana, quinta edición, Madrid, Imprenta Real.

DRAE 1822 = REAL ACADEMIA ESPAÑOLA (1822): Diccionario de la lengua castellana, sexta edición, Madrid: Imprenta Nacional.

DRAE 1832 = REAL ACADEMIA ESPAÑOLA (1832): Diccionario de la lengua castellana, séptima edición, Madrid: Imprenta Real.

DRAE 1837 = REAL ACADEMIA ESPAÑOLA (1837): Diccionario de la lengua castellana, octava edición, Madrid: Imprenta Nacional.

DRAE 1884 = REAL ACADEMIA ESPAÑOLA (1884): Diccionario de la lengua castellana, duodécima edición, Madrid: Imprenta de D. Gregorio Hernando.

Jiménez Ríos, E. (2001): Variación léxica y diccionario: los arcaísmos en el diccionario de la Academia, Madrid: Iberoamericana.

Morales Ruiz, Carmen (1998): «Las relaciones del léxico en el diccionario», Cuadernos de Filología 1: 1-41, Bellaterra: Universitat Autònoma de Barcelona, Serveis de Publicacions. 
Muñoz, Laura (2018): «La sinonimia y las remisiones», en G. Clavería y M. Freixas (coords.), El diccionario de la Academia en el siglo XIX: la 5. a edición (1817) al microscopio, Madrid: Arco/ Libros, 203-221.

Pascual Fernández, María Luisa (2019): «Remisiones con lo mismo que, un ensayo en la gestación del diccionario académico", en Actas del X Congreso Internacional de Historia de la Lengua Española (Zaragoza, 7-11 de septiembre de 2015), Zaragoza: Universidad de Zaragoza, 1261-1272.

Porto Dapena, José-Álvaro (2002): «La definición lexicográfica», en Manual de técnica lexicográfica, cap. 8, Madrid: Arco/Libros.

Regueiro Rodríguez, María Luisa (2010): «La sinonimia», Cuadernos de lengua española 119, Madrid: Arco/Libros.

Rey-Debove, Josette (1989): «Les systèmes de renvois dans le dictionnaire monolingue», en F.J. Hausmann et al. (eds.), Wörterbücher. Ein internationales Handbuch zur Lexicographie, vol. II, Berlin-New York: Walter de Gruyter, 931-936.

Terrón, Natalia (2019): «Historia de la lengua y lexicografía: el aumento de voces en la 6. ${ }^{a}$ edición del Diccionario de la Academia (1822)», en Actas del X Congreso Internacional de Historia de la Lengua Española (7-11 de septiembre de 2015), Zaragoza: Universidad de Zaragoza, 1325-1341.

Trujillo, Ramón (1994): «El diccionario frente a la semántica», en H. Hernández Hernández, (coord.), Aspectos de lexicografía contemporánea, Barcelona, Biblograf., 73-93. 
